\title{
Evaluating high temperature elastic modulus of ceramic coatings by relative method
}

\author{
Guanglin NIE, Yiwang BAO*, Detian WAN, Yuan TIAN \\ State Key Laboratory of Green Building Materials, China Building Materials Academy, Beijing 100024, China
}

Received: June 16, 2017; Revised: August 07, 2017; Accepted: August 09, 2017

(C) The Author(s) 2017. This article is published with open access at Springerlink.com

\begin{abstract}
The accurate evaluation of the elastic modulus of ceramic coatings at high temperature (HT) is of high significance for industrial application, yet it is not easy to get the practical modulus at HT due to the difficulty of the deformation measurement and coating separation from the composite samples. This work presented a simple approach in which relative method was used twice to solve this problem indirectly. Given a single-face or double-face coated beam sample, the relative method was firstly used to determine the real mid-span deflection of the three-point bending piece at HT, and secondly to derive the analytical relation among the HT moduli of the coating, the coated and uncoated samples. Thus the HT modulus of the coatings on beam samples is determined uniquely via the measured HT moduli of the samples with and without coatings. For a ring sample (from tube with outer-side, inner-side, and double-side coating), the relative method was used firstly to determine the real compression deformation of a split ring sample at HT, secondly to derive the relationship among the slope of load-deformation curve of the coated ring, the HT modulus of the coating and substrate. Thus, the HT modulus of ceramic coatings can be evaluated by the substrate modulus and the load-deformation data of coated rings. Mathematic expressions of those calculations were derived for the beam and ring samples. CVD-SiC coatings on graphite substrate were selected as the testing samples, of which the measured modulus ranging from room temperature to $2100{ }^{\circ} \mathrm{C}$ demonstrated the validity and convenience of the relative method.
\end{abstract}

Keywords: elastic modulus; ceramic coatings; high temperature (HT); relative method; $\mathrm{SiC}$

\section{Introduction}

Ceramic coatings have attracted considerable attention of material scientists and mechanical engineers due to their wide applications in aerospace, aviation, energy, petrochemical, and chemical industry fields to withstand high temperature (HT) [1-3]. The HT ceramic coatings are used for three main functions, viz. 1) to protect the substrates against corrosion or

* Corresponding author.

E-mail: ywbao@ctc.ac.cn oxidation; 2) to minimize the wear; 3) to reduce the heating damage of substrates [4-8]. The HT elastic modulus of coatings is one of the important parameters for the security and reliability of coating/substrate composite components. For example, the level of residual stress is influenced by the mismatch of elastic modulus between coating and substrate materials [9], and the strength of the bonded system is also governed by the elastic mismatch [10]. However, there exists great challenge in evaluating the modulus of ceramic coatings, especially at high and ultrahigh temperature.

Previous studies on the HT elastic modulus of the 
ceramic coatings mainly involve three aspects. 1) It is to study the effect of HT treatment on the coating modulus. The coatings were cooled to ambient temperature after thermal exposure at HT, and the modulus was determined by ultrasonic or nanoindentation method at room temperature $[11,12] .2)$ It is to measure the HT modulus of the free-standing coatings by common test methods used for bulk materials after stripping the coatings from the substrates [13-15]. Yet it is difficult for thin ceramic coatings because most of them are tightly bonded on substrates and hardly separated from the substrates. 3) It is to utilize the indentation method directly to evaluate HT modulus of coatings at temperatures below $1000{ }^{\circ} \mathrm{C}$ [16-18]. However, the drawback stems from the oxidation, erosion, and stiffness degradation of the indenter at HT that affect deeply the measurements $[19,20]$. Additionally, the indention method only measures the local modulus that is different from the practical modulus, especially when the coating structure is inhomogeneous [21]. Therefore, it is urgent and significant to develop feasible approaches to evaluate the practical elastic modulus of ceramic coatings at high or ultrahigh temperature.

Usually, the product forms of HT components with coatings are plates or tubes. For example, the blades of the gas turbine engines, with surface thermal barrier ceramic coatings, are plate-like structure [22]. And parts of the wing leading edge on re-entry vehicles with protective coatings are platy in structure [23]. In addition, the coated tubular components are often used at $\mathrm{HT}$ and the coatings are required to be on the inside or outside surface of the tubes. For instance, the thermal sprayed coatings are on the out wall of boiler tubes [24,25], and some HT coatings are on the inner surface of the nozzle wall, gun barrel, and engine cylinder liners [26-30]. Also the enamel coatings are applied on both inside and outside surfaces of the combustor liners [31]. For the coatings on the tubular or circular parts, they are hardly machined into the beam or plate samples. It is of great significance to test the elastic modulus of the tubular coatings without changing the shape of the components. Therefore, it is in great need to develop methods to measure the elastic modulus of coatings on beam and tube samples.

Since conventional method is difficult to measure the modulus of ceramic coatings at HT, the relative method is considered as an effective solution. The relative method is a kind of technical consideration of an indirect test, in which the less measurable parameters can be determined from the directly testable parameters [32-34]. The bending method and split ring method are usually used to measure the modulus of monolithic beams and ceramic tubes at room temperature, respectively [35-38]. In this work, the bending method and relative method were combined together to estimate the HT elastic modulus of coatings on beam samples, and the HT modulus of coatings on ring samples was determined by using the split ring method and relative method in combination. By comparing the difference between the cross-beam displacement of test sample and rigid reference piece under the identical loads [39], the relative method was utilized for the first time to obtain the accurate deflection or deformation of the bending piece or split ring sample at HT. Thus, the HT modulus of coated and uncoated samples can be measured. And the relative method was used for the second time to deduce analytical formula of the coating modulus from the comparison between the mechanical responses of coated and uncoated samples. The approach needs to use relative method twice in the present research and it is convenient and reliable for determining HT elastic modulus of ceramic coatings. The main measuring steps of this method are: 1) determining the real HT deformation of test sample by the relative method via three-point bending test or split ring compressing experiment, 2) evaluating elastic modulus of the monolithic beam or split ring samples through the load and accurate deformation, and 3) evaluating elastic modulus of coatings via the deduced analytical relations.

\section{Basic principles}

\section{1 Determining HT elastic modulus of coatings on beam samples}

For a beam sample, the three-point bending test is widely used to evaluate the elastic modulus through the ratio of load-increment $\Delta P$ to deflection increment $\Delta f[32]$ :

$$
E=\frac{L^{3}}{4 H^{3} b} \cdot \frac{\Delta P}{\Delta f}
$$

where $L$ is the span in mm, $H$ and $b$ are the thickness and width of the sample in mm respectively. When the unit of $\Delta P$ is $\mathrm{N}$ and the unit of $\Delta f$ is $\mathrm{mm}$, the unit of the calculated modulus $E$ is $\mathrm{MPa}$. 
$\Delta f$ can be obtained by the accurate inductance micrometer or other displacement meter at ambient temperature. However, $\Delta f$ is hardly measured by the devices in harsh thermal environment directly. In order to acquire the accurate mid-span deflection at HT, a simple relative method is introduced. Based on the relative method, a bending test sample with two support bars and a reference sample without support bars should be the same size and loaded under the identical testing conditions, as shown in Fig. 1. Two displacements of the cross-beam, $\Delta f_{1}$ and $\Delta f_{2}$, will be obtained for the test sample (Fig. 1(a)) and the reference sample (Fig. 1(b)) under the same $\Delta P$. Since the bending deformation of the reference sample can be ignored, $\Delta f_{2}$ can just represent the systematic errors of loading
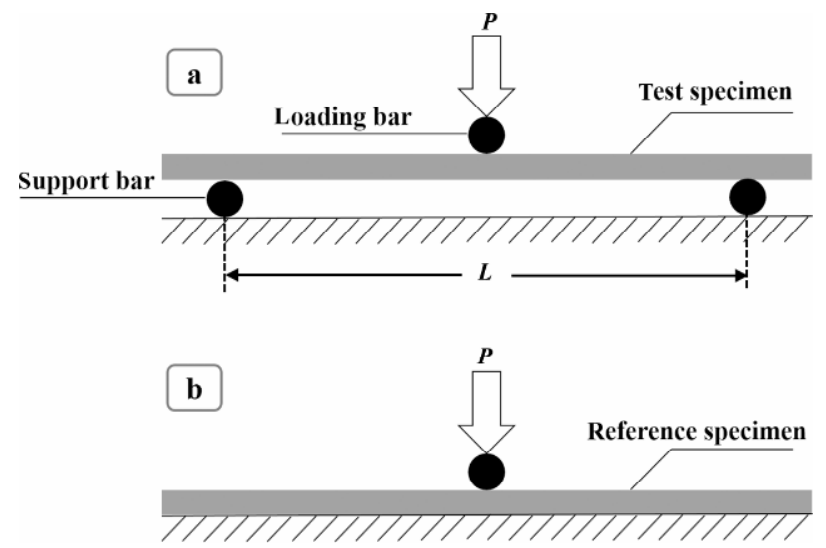

Fig. 1 Test schematic illustration of the real high temperature deflection: (a) normal three-point bending test, (b) error corrected test. system generated by the testing system flexibility and the contact displacement of specimen and fixture. Thus, the difference of cross-beam displacements between the test sample and reference sample, denoted as $\Delta f_{1}-\Delta f_{2}$, is equal to the real deflection of the bending specimen under the given load-increment. The HT elastic modulus of beam sample can be determined via the following equation:

$$
E_{\mathrm{H}}=\frac{L^{3}}{4 H^{3} b} \cdot \frac{\Delta P}{\Delta f_{1}-\Delta f_{2}}
$$

here, $E_{\mathrm{H}}$ is the HT elastic modulus of the beam piece in $\mathrm{MPa}$.

In this work, two common coating patterns on beams were discussed: 1) single-face coating (Fig. 2(a)) and 2) double-face coating (Fig. 2(b)). To get the accurate deformations of the coated beam samples at HT, the reference specimens with the same size as the coated test pieces are needed. In the present research, the elastic moduli of the uncoated and coated samples were defined as $E_{\mathrm{s}}$ and $E_{\mathrm{q}}$, respectively. $E_{\mathrm{s}}$ and $E_{\mathrm{q}}$ can be measured by Eq. (2) at HT. Let the modulus of coatings be $E_{\mathrm{f}}$. The ratio of modulus was defined by $\alpha=E_{\mathrm{f}} / E_{\mathrm{s}}$.

\section{1. 1 Determining HT modulus of single-face coatings on beam samples}

For the single-face coated piece as shown in Fig. 2(a), its HT elastic modulus $\left(E_{\mathrm{q}}\right)$ can be obtained by using the relative method and Eq. (2):

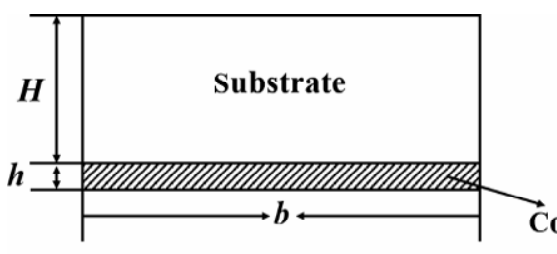

(a)

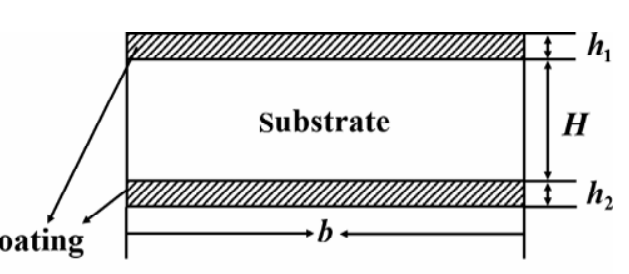

(b)

Fig. 2 Schematic illustration of cross-sections of beam specimens with different coating configurations: (a) single-face coating, (b) double-face coating.

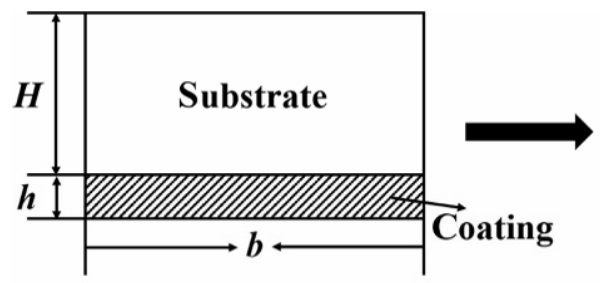

(a)

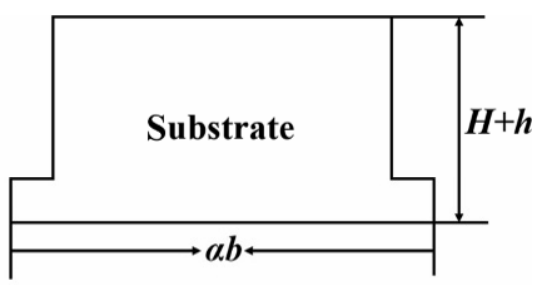

(b)

Fig. 3 Schematics of the cross-section transformations of a single-face coated sample: (a) heterogeneous cross-section, (b) homogeneous section. 


$$
E_{\mathrm{q}}=\frac{L^{3}}{4(H+h)^{3} b} \cdot \frac{\Delta P}{\Delta f_{\mathrm{q} 1}-\Delta f_{\mathrm{q} 2}}
$$

Here, $b$ is the width of the coated piece, $H$ and $h$ the thickness of the substrate and coating respectively. $\Delta f_{\mathrm{q} 1}$ and $\Delta f_{\mathrm{q}^{2}}$ are the deflection increments of the test coated piece and reference sample under the same load increment $(\Delta P)$, respectively.

Based on the material mechanics, the heterogeneous cross-section (Fig. 3(a)) can be converted into the homogeneous one (Fig. 3(b)) consisted only of the substrate material by the principle of equivalent stiffness [40].

Evidently, the bending stiffness of the heterogeneous cross-section beam sample is the same as that of the homogeneous section beam specimen. Naturally, the mid-span deflections of the two beam samples will be equivalent under the same load.

$$
f=\frac{P L^{3}}{48 E_{\mathrm{q}} I}=\frac{P L^{3}}{48 E_{\mathrm{s}} I_{1}}
$$

Here, $I$ is the inertia moment of the heterogeneous beam sample with coating, $I_{1}$ the inertia moment of the equivalent homogeneous sample, and $f$ the mid-span deflection. Equation (4) can be simplified to

$$
E_{\mathrm{q}} I=E_{\mathrm{s}} I_{1}
$$

Based on the theory of material mechanics [41], $I$ and $I_{1}$ have the form:

$$
\begin{aligned}
& I=\frac{1}{12} b(H+h)^{3} \\
& I_{1}=\frac{1}{12} b H^{3}+\frac{1}{12} b h^{3} \alpha+\frac{1}{4} \alpha b H h \frac{(H+h)^{2}}{H+\alpha h}
\end{aligned}
$$

Combining Eq. (5) and Eq. (6), a simplified relation is derived by

$$
\xi_{1} \alpha^{2}+\xi_{2} \alpha+\xi_{3}=0
$$

where $\xi_{1}=\frac{1}{12} h^{4}$,

$$
\xi_{2}=\frac{1}{12} H h^{3}+\frac{1}{4} H h(H+h)^{2}-\frac{E_{\mathrm{q}} h(H+h)^{3}-E_{\mathrm{s}} h H^{3}}{12 E_{\mathrm{s}}},
$$

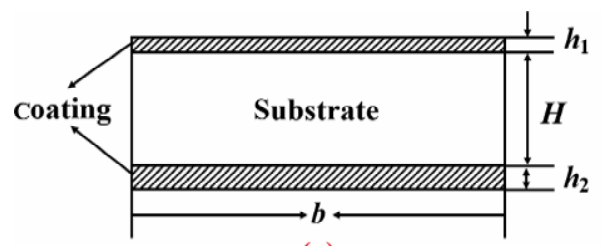

(a) and $\xi_{3}=-\frac{E_{\mathrm{q}} H(H+h)^{3}-E_{\mathrm{s}} H^{4}}{12 E_{\mathrm{s}}}$. As $E_{\mathrm{q}}$ and $E_{\mathrm{s}}$ can be obtained by Eq. (2) at HT, $\alpha$ is determined by the following equation:

$$
\alpha=\frac{\sqrt{\xi_{2}^{2}-4 \xi_{1} \xi_{3}}-\xi_{2}}{2 \xi_{1}}
$$

Hence, the modulus of the coatings is calculated by

$$
E_{\mathrm{f}}=\frac{\sqrt{\xi_{2}^{2}-4 \xi_{1} \xi_{3}}-\xi_{2}}{2 \xi_{1}} E_{\mathrm{s}}
$$

\section{1. 2 Determining HT modulus of double-face coatings on beam samples}

For the double-face coated sample as shown in Fig. 2(b), the elastic modulus of the composite system $\left(E_{\mathrm{q}}\right)$ can be measured by the relative method and Eq. (2):

$$
E_{\mathrm{q}}=\frac{L^{3}}{4\left(H+h_{1}+h_{2}\right)^{3} b} \cdot \frac{\Delta P}{\Delta f_{\mathrm{q} 1}-\Delta f_{\mathrm{q} 2}}
$$

Here, $h_{1}$ and $h_{2}$ are the thickness of the upper and lower coating, respectively.

According to the equivalent stiffness concept [40], the heterogeneous cross-section (Fig. 4(a)) can be converted into the homogeneous one (Fig. 4(b)) for which the width of coating is multiplied by $\alpha$ times and the modulus of the homogeneous piece has the same value as the substrate. The distance from the lower coating surface (tensile surface) to the neutral axis, $y_{c}$, has the form:

$$
y_{\mathrm{c}}=\frac{\left[\frac{1}{2} h_{2}^{2}+h_{1}\left(H+h_{2}+\frac{1}{2} h_{1}\right)\right] \alpha+H\left(h_{2}+\frac{H}{2}\right)}{\left(h_{1}+h_{2}\right) \alpha+H}
$$

Based on the theory of material mechanics [41], the inertia moments of the heterogeneous and homogeneous sections, $I$ and $I_{1}$, have the forms:

$$
I=\frac{1}{12} b\left(H+h_{1}+h_{2}\right)^{3}
$$

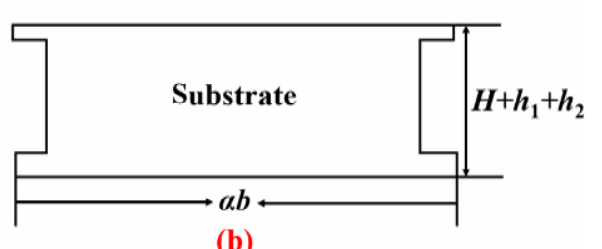

(b)

Fig. 4 Schematics of the equivalent cross-section transformations of a double-face coated sample: (a) heterogeneous cross-section, (b) homogeneous section. 


$$
\begin{aligned}
I_{1} & =\frac{1}{12} \alpha b h_{2}^{3}+\alpha b h_{2}\left(y_{\mathrm{c}}-\frac{h_{2}}{2}\right)^{2}+\frac{1}{12} b H^{3}+b H\left(\frac{H}{2}+h_{2}-y_{\mathrm{c}}\right)^{2} \\
& +\frac{1}{12} \alpha b h_{1}^{3}+\alpha b h_{1}\left(H+h_{2}+\frac{h_{1}}{2}-y_{\mathrm{c}}\right)^{2}
\end{aligned}
$$

The coated beam with sections Fig. 4(a) and Fig. 4(b) has the same stiffness. A simplified relation is derived by substituting Eq. (12) into Eq. (5).

$$
\kappa_{1} \alpha^{3}+\kappa_{2} \alpha^{2}+\kappa_{3} \alpha+\kappa_{4}=0
$$

where $\kappa_{1}-\kappa_{4}$ are the coefficients of the cubic equation of one unknown and can be calculated by

$$
\begin{aligned}
\kappa_{1}= & b h_{1} h_{2}\left(h_{1}+h_{2}\right)\left(2 H+h_{1}+h_{2}\right)^{2}+\frac{b}{3}\left(h_{1}^{3}+h_{2}^{3}\right)\left(h_{1}+h_{2}\right)^{2} \\
\kappa_{2}= & 2 b h_{1} h_{2} H\left(2 H+h_{1}+h_{2}\right)^{2}+\frac{2}{3} b H\left(h_{1}^{3}+h_{2}^{3}\right)\left(h_{1}+h_{2}\right) \\
& +b H\left(h_{2}-h_{1}\right)^{2}\left(H+h_{1}+h_{2}\right)^{2} \\
& -\frac{b}{3}\left[\frac{E_{\mathrm{q}}}{E_{\mathrm{s}}}\left(H+h_{1}+h_{2}\right)^{3}-H^{3}\right]\left(h_{1}+h_{2}\right)^{2} \\
\kappa_{3}= & H^{2} b\left[h_{2}\left(h_{2}+H\right)^{2}+\frac{1}{3}\left(h_{1}^{3}+h_{2}^{3}\right)+h_{1}\left(h_{1}+H\right)^{2}\right] \\
& -\frac{2 b H}{3}\left[\frac{E_{\mathrm{q}}}{E_{\mathrm{s}}}\left(H+h_{1}+h_{2}\right)^{3}-H^{3}\right]\left(h_{1}+h_{2}\right) \\
\kappa_{4}= & -\frac{b H^{2}}{3}\left[\frac{E_{\mathrm{q}}}{E_{\mathrm{s}}}\left(H+h_{1}+h_{2}\right)^{3}-H^{3}\right]
\end{aligned}
$$

Thus, the value of $\alpha$ can be obtained by solving Eq. (13) via the calculator of univariate cubic equation or MATLAB software, noting that $\alpha$ is a real number and $\alpha>0$. Then the HT modulus of coatings can be evaluated by $E_{\mathrm{f}}=\alpha E_{\mathrm{s}}$.

Obviously, the HT elastic modulus of coatings on beam pieces can be evaluated by the coated samples' geometrical dimensions and the HT modulus of the coated and uncoated samples. Notably, the relative method is used twice, i.e., first to measure the HT modulus of the coated and uncoated samples via Eq. (2), and then to evaluate the HT elastic modulus of coatings via Eq. (9) or Eq. (13). The three-point bending experiments for determining the HT modulus of coatings by this novel relative method are performed in the following steps: 1) remove the coatings and prepare the substrate samples by grinding or cutting, 2) manufacture the reference samples which have the same size as the substrates and coated samples, 3) record the cross-beam displacement of the test pieces and reference samples under identical load-increment at the same setting temperature, 4) calculate the HT modulus of substrates and coated samples by Eq. (2), and 5) finally calculate the values of $E_{\mathrm{f}}$ by Eq. (9) for single-face coating or Eq. (13) for double-face coating.

\section{2 Determining HT elastic modulus of coatings on ring samples}

The accurate evaluation of the modulus of the test pieces is very crucial to the determination of the coating modulus. According to the research results of Ref. [32], the ratio of $E_{\mathrm{q}}$ to $E_{\mathrm{s}}\left(E_{\mathrm{q}} / E_{\mathrm{s}}\right)$ has a significant influence on the value of $\alpha$. For instance, the value of $\alpha$ calculated by the measured $E_{\mathrm{q}} / E_{\mathrm{s}}$ of 2.4 is $31.29 \%$ higher than that computed by the measured $E_{\mathrm{q}} / E_{\mathrm{s}}$ of 2.2 , with $h / H$ value of 0.005 . That is, only $9.09 \%$ increase of the measured $E_{\mathrm{q}} / E_{\mathrm{s}}$ leads to $31.29 \%$ rise of the calculated value of $\alpha$ for the composite with a thin coating. So the accurate measurement of the modulus of uncoated and coated pieces has a significant impact on the estimation of the modulus of coatings. The more accurate test results of elastic modulus of the tube or ring materials will be obtained by the split ring compressing tests with the consideration of the effect of axial and shear stress. That is, the split ring specimen is suffered with bending moment, axial and shear stress under the compressive load. According to the force analysis of split ring sample as shown in Fig. 5, the internal forces of any section of the sample have the forms:

$$
N=-P \sin \varphi, Q=-P \cos \varphi, M=P R_{0} \sin \varphi
$$

where $N$ is the axial force, $Q$ the shear force, $M$ the bending moment, $P$ the applied load, $\varphi$ the angle between the cross-section and the vertical line, and $R_{0}$ the curvature radius of geometrical centroidal axis of the cross-section.

Take the derivative of the above internal forces by the

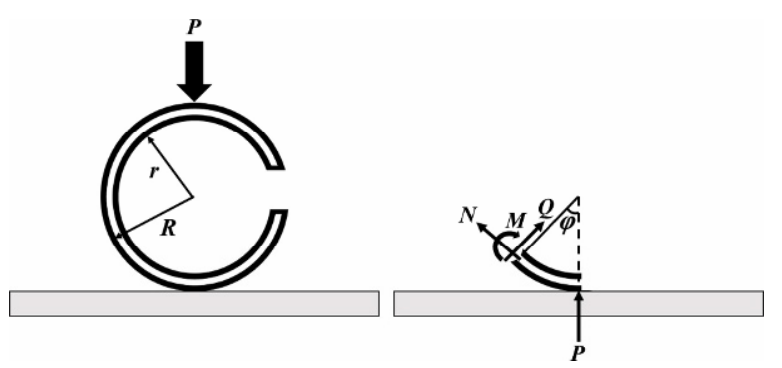

Fig. 5 Schematic diagram of force analysis of the split ring specimen. 
applied load:

$$
\frac{\partial N}{\partial P}=-\sin \varphi, \frac{\partial Q}{\partial P}=-\cos \varphi, \frac{\partial M}{\partial P}=R_{0} \sin \varphi
$$

The deformation energy of the split ring sample in the compression process can be determined by the following equation:

$$
U=\int_{0}^{\pi}\left(\frac{M^{2}}{2 E S R_{0}}+\frac{M N}{E A R_{0}}+\frac{N^{2}}{2 E A}+\frac{k Q^{2}}{2 G A}\right) R_{0} \mathrm{~d} \varphi
$$

here, $E$ is the elastic modulus, $S$ the static moment of the entire cross-section to the neutral axis, $G$ the shear modulus, $k$ a geometric constant dependent on the shape of cross-section. Based on the material mechanics [41], $k=1.2$ for a rectangular section.

Based on Castigliano's theorem [41], the vertical displacement of the force acting point during elastic deformation range is derived by

$$
\begin{aligned}
\Delta \delta=\frac{\partial U}{\partial P}=\int_{0}^{\pi} & \left(\frac{M}{E S R_{0}} \frac{\partial M}{\partial P}+\frac{M}{E A R_{0}} \frac{\partial N}{\partial P}+\frac{M}{E A R_{0}} \frac{\partial M}{\partial P}\right. \\
& \left.+\frac{N}{E A} \frac{\partial N}{\partial P}+\frac{k Q}{G A} \frac{\partial Q}{\partial P}\right) R_{0} \mathrm{~d} \varphi
\end{aligned}
$$

Combining Eq. (16) and Eq. (18), and noting that $G=E /[2(1+v)]$, a general expression for $E$ can be obtained:

$$
E=\frac{\pi R_{0}}{2 A} \cdot \frac{\Delta P}{\Delta \delta} \cdot\left(\frac{R_{0}}{e}+2.4 v+1.4\right)
$$

where $\Delta P / \Delta \delta$ is the slope of load-displacement curve during the elastic deformation range, $e$ the distance between the geometrical centroidal axis and neutral layer, $A$ the area of the cross-section, $v$ Poisson's ratio of materials. Poisson's ratio of 0.2 is used for most brittle materials, such as ceramics and glass. And the parameters in Eq. (19) can be determined via the geometrical dimensions of the sample:

$$
R_{0}=\frac{R+r}{2}, A=b(R-r), e=\frac{R+r}{2}-\frac{R-r}{\ln \left(\frac{R}{r}\right)}
$$

where $R$ is the outer radius, $r$ the inner radius, and $b$ the width (axial length) of split ring specimen.

Thus to obtain the accurate HT deformation of the sample, $\Delta \delta$ is seen as the critical issue for evaluating the HT elastic moduli. Based on the relative method [39], a rigid disk which has the same outer diameter and width as the split ring test piece is considered as the reference sample. At HT, the real deformation of a test piece can be obtained through comparing the measured cross-beam displacements between the test piece and a reference specimen under the same load, as shown in Fig. 6. Two cross-beam displacements, $\Delta \delta_{1}$ and $\Delta \delta_{2}$, will be obtained for the split ring and rigid disk under a fixed load-increment, $\Delta P$, respectively. The stiffness of the rigid disk is much higher than that of the split ring piece, so the deformation of the rigid disk under $\Delta P$ can be ignored and its cross-beam displacement $\left(\Delta \delta_{2}\right)$ can represent the systematic errors of loading system which are induced by the loading frame, fixture, loading device, and contact deformation. Thus, the difference of the displacements between the split ring and the rigid disk is equal to the real deformation of the split ring test piece at HT.

$$
\Delta \delta=\Delta \delta_{1}-\Delta \delta_{2}
$$

By substituting Eq. (21) into Eq. (19), the HT modulus of the test piece can be obtained:

$$
E_{\mathrm{H}}=\frac{\pi R_{0}}{2 A} \cdot \frac{\Delta P}{\Delta \delta_{1}-\Delta \delta_{2}} \cdot\left(\frac{R_{0}}{e}+2.4 v+1.4\right)
$$

where $E_{\mathrm{H}}$ is the elastic modulus of test specimen at HT.

In this work, three common coating patterns on tubes were discussed: outer-side coating (Fig. 7(a)), inner-side coating (Fig. 7(b)), and double-side coating (Fig. 7(c)). To get the accurate deformations of the coated split ring samples at HT, the rigid reference disks with the same outer radius and width as the coated pieces are needed.

\subsubsection{Determining HT modulus of outer-side coatings on ring samples}

For a split specimen with outer-side coating as shown in Fig. 7(a), a relationship between the modulus of the substrate, $\Delta P / \Delta \delta$, and geometrical dimensions of coated sample can be obtained by rearranging Eq. (19) based on the concepts of equivalent stiffness.
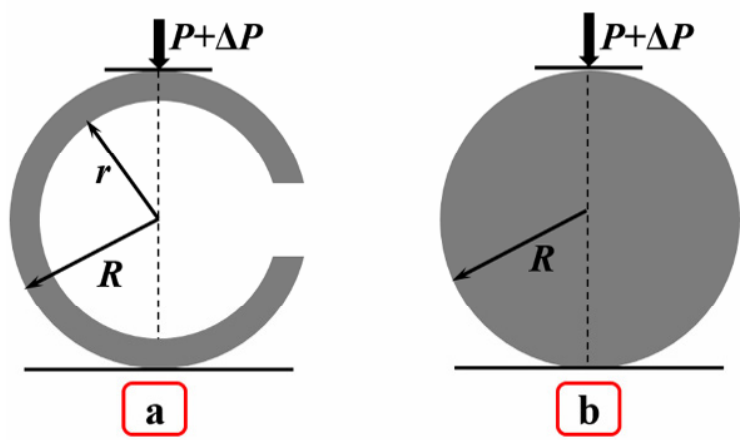

Fig. 6 Schematic diagram of (a) the split ring and (b) the rigid reference disk. 


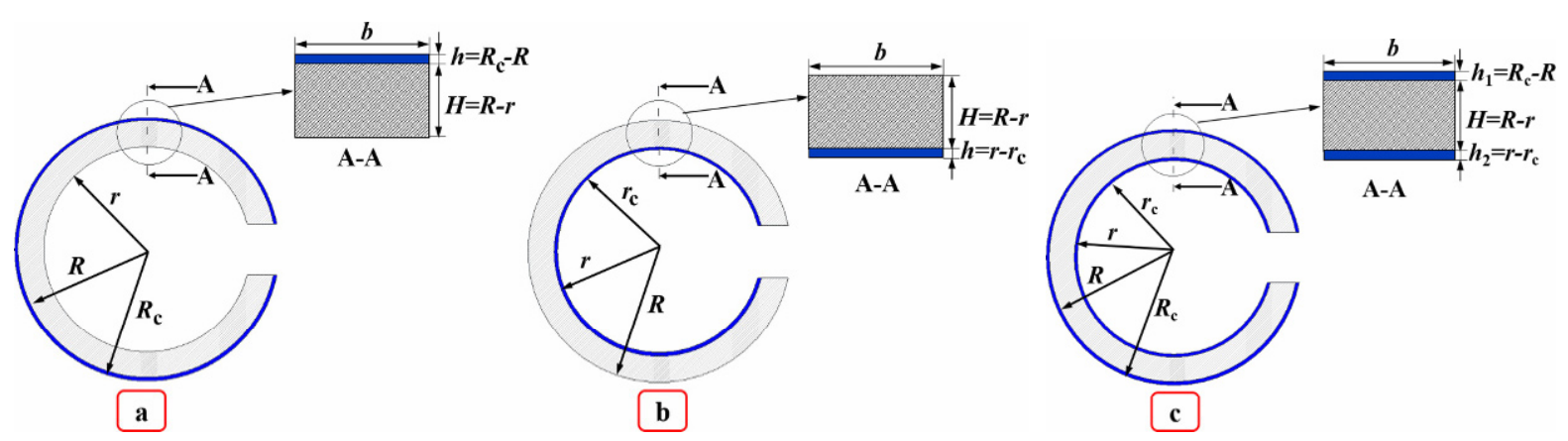

Fig. 7 Schematic illustration of split ring specimen with (a) outer-side coating, (b) inner-side coating, and (c) double-side coating.

$$
\frac{2 E_{\mathrm{s}}}{\pi} \frac{\Delta \delta}{\Delta P}=\frac{R_{0}^{\prime}}{A^{\prime}}\left(\frac{R_{0}^{\prime}}{e^{\prime}}+2.4 v+1.4\right)
$$

Here, $E_{\mathrm{s}}$ is the modulus of the substrate, $\Delta \delta$ the real compression deformation of the substrate/coating composite system, $R_{0}^{\prime}$ the curvature radius of geometrical centroidal axis of the homogeneous equivalent cross-section of the coated sample, $e^{\prime}$ the distance between centroidal axis and neutral layer of the equivalent composite cross-section, and $A^{\prime}$ the area of the equivalent composite cross-section.

Assuming the cross-beam displacement of coated sample is $\Delta \delta_{3}$ under the fixed load-increment $\Delta P$ at HT, the real HT deformation of the coated piece is $\Delta \delta=\Delta \delta_{3}-\Delta \delta_{2}$, and Eq. (23) can be rewritten as

$$
\frac{2 E_{\mathrm{sH}}}{\pi} \frac{\Delta \delta_{3}-\Delta \delta_{2}}{\Delta P}=\frac{R_{0}^{\prime}}{A^{\prime}}\left(\frac{R_{0}^{\prime}}{e^{\prime}}+2.4 v+1.4\right)
$$

where $E_{\mathrm{sH}}$ is the HT modulus of the substrate. As shown in Fig. 7(a), $r$ is the inner radius of the substrate, $R$ is the outer radius of the substrate, $R_{\mathrm{c}}$ is the outer radius of the outer-side coating, and $b$ is the width of composite specimen. Through the geometrical analysis of the composite section, the calculation formulas of $R_{0}^{\prime}, e^{\prime}$, and $A^{\prime}$ are acquired via a method of equivalent stiffness.

$$
\begin{aligned}
& R_{0}^{\prime}=\frac{\alpha h H+0.5 \alpha h^{2}+0.5 H^{2}}{H+\alpha h}+r \\
& e^{\prime}=\frac{\alpha h H+0.5 \alpha h^{2}+0.5 H^{2}}{H+\alpha h}+r-\frac{\alpha h+H}{\ln \left(\frac{R}{r}\right)+\alpha \ln \left(\frac{R+h}{R}\right)}
\end{aligned}
$$$$
A^{\prime}=b H+\alpha b h
$$

Here, $H$ is the thickness of the substrate and $H=R-r$, $h$ is the thickness of outer-side coating and $h=R_{\mathrm{c}}-R$. Combining Eq. (25) and Eq. (24), a relationship among
$E_{\mathrm{sH}}, \Delta P / \Delta \delta$, and $\alpha$ is given by

$$
\beta_{1} \alpha^{4}+\beta_{2} \alpha^{3}+\beta_{3} \alpha^{2}+\beta_{4} \alpha+\beta_{5}=0
$$

where $\beta_{1}-\beta_{5}$ are constants determined by

$\beta_{1}=\left(B_{13}-B_{7}\right) h^{2}$

$\beta_{2}=\left(B_{14}-B_{8}\right) h^{2}+2 H h\left(B_{13}-B_{7}\right)-B_{2} B_{10}$

$\beta_{3}=\left(B_{13}-B_{7}\right) H^{2}+\left(B_{15}-B_{9}\right) h^{2}+2 H h\left(B_{14}-B_{8}\right)$

$-B_{1} B_{10}-B_{2} B_{11}$

$\beta_{4}=\left(B_{14}-B_{8}\right) H^{2}+2 H h\left(B_{15}-B_{9}\right)-B_{1} B_{11}-B_{2} B_{12}$

$\beta_{5}=\left(B_{15}-B_{9}\right) H^{2}-B_{1} B_{12}$

where $B_{0}=\frac{2 E_{\mathrm{sH}} b}{\pi} \cdot \frac{\Delta \delta_{3}-\Delta \delta_{2}}{\Delta P}, \quad B_{1}=\ln \left(\frac{R}{r}\right), \quad B_{2}=$ $\ln \left(\frac{R+h}{R}\right), B_{3}=H h+\frac{1}{2} h^{2}, B_{4}=\frac{1}{2} H^{2}, \quad B_{5}=B_{0} B_{4}+$ $B_{0} r H-(2.4 v+2.4) r^{2}, B_{6}=B_{0} B_{3}+B_{0} r h, B_{7}=B_{0} h^{2}$, $B_{8}=2 B_{0} H h-(2.4 v+1.4)\left(B_{3}+h r\right), B_{9}=B_{0} H^{2}-(2.4 v$ $+1.4)\left(B_{4}+H r\right), B_{10}=(2.4 v+2.4) B_{3}^{2}+(4.8 v+4.8) r B_{3} h$, $B_{11}=(4.8 v+4.8)\left(B_{3} B_{4}+r B_{3} H+r h B_{4}\right), B_{12}=(2.4 v$. $+2.4) B_{4}^{2}+(4.8 v+4.8) B_{4} H r, B_{13}=B_{2} B_{6}, B_{14}=B_{1} B_{6}$ $+B_{2} B_{5}, B_{15}=B_{1} B_{5}$.

Thus, the value of $\alpha$ can be obtained by solving Eq. (26) via the calculator of quartic equation or MATLAB software, noting that $\alpha$ is a real number and $\alpha>0$. Then the HT modulus of coatings can be evaluated by

$$
E_{\mathrm{f}}=\alpha E_{\mathrm{sH}}
$$

\subsubsection{Determining HT modulus of inner-side coatings on ring samples}

For a split ring piece with inner-side coating as shown in Fig. 7(b), assuming its cross-beam displacement is $\Delta \delta_{4}$ under the fixed load-increment $\Delta P$ at HT, the real HT deformation of the coated piece is $\Delta \delta=\Delta \delta_{4}-\Delta \delta_{2}$. Thus, Eq. (23) can be rewritten as 


$$
\frac{2 E_{\mathrm{sH}}}{\pi} \frac{\Delta \delta_{4}-\Delta \delta_{2}}{\Delta P}=\frac{R_{0}^{\prime}}{A^{\prime}}\left(\frac{R_{0}^{\prime}}{e^{\prime}}+2.4 v+1.4\right)
$$

As shown in Fig. 7(b), $r_{\mathrm{c}}$ is the inner radius of the inner-side coating. The geometrical analysis of the composite cross-section is conducted and $R_{0}^{\prime}$ and $e^{\prime}$ have the forms:

$$
\begin{aligned}
& R_{0}^{\prime}=\frac{0.5 \alpha h^{2}+0.5 H^{2}+h H}{H+\alpha h}+r_{\mathrm{c}} \\
& e^{\prime}=\frac{0.5 \alpha h^{2}+0.5 H^{2}+h H}{H+\alpha h}+r_{\mathrm{c}}-\frac{\alpha h+H}{\ln \left(\frac{R}{r}\right)+\alpha \ln \left(\frac{r}{r_{\mathrm{c}}}\right)}
\end{aligned}
$$

here, $H$ is the thickness of the substrate and $H=R-r$, $h$ is the thickness of the inner-side coating and $h=r-r_{\text {c }}$. Combining Eqs. (29) and (30), a simplified relation among $E_{\mathrm{sH}}, \Delta P / \Delta \delta$, and $\alpha$ is derived by

$$
\eta_{1} \alpha^{4}+\eta_{2} \alpha^{3}+\eta_{3} \alpha^{2}+\eta_{4} \alpha+\eta_{5}=0
$$

where $\eta_{1}-\eta_{5}$ are the coefficients of the quartic equation and can be calculated by

$$
\begin{aligned}
\eta_{1}= & \left(C_{13}-C_{7}\right) h^{2} \\
\eta_{2}= & \left(C_{14}-C_{8}\right) h^{2}+2 H h\left(C_{13}-C_{7}\right)-C_{4} C_{10} \\
\eta_{3}= & \left(C_{13}-C_{7}\right) H^{2}+\left(C_{15}-C_{9}\right) h^{2}+2 H h\left(C_{14}-C_{8}\right) \\
& -C_{3} C_{10}-C_{4} C_{11} \\
\eta_{4}= & \left(C_{14}-C_{8}\right) H^{2}+2 H h\left(C_{15}-C_{9}\right)-C_{3} C_{11}-C_{4} C_{12} \\
\eta_{5}= & \left(C_{15}-C_{9}\right) H^{2}-C_{3} C_{12}
\end{aligned}
$$

where $C_{0}=\frac{2 E_{\mathrm{sH}} b}{\pi} \cdot \frac{\Delta \delta_{4}-\Delta \delta_{2}}{\Delta P}, C_{1}=\frac{1}{2} h^{2}$, $C_{2}=\frac{1}{2} H^{2}+H h, C_{3}=\ln \left(\frac{R}{r}\right), C_{4}=\ln \left(\frac{r}{r_{\mathrm{c}}}\right)$,

$C_{5}=C_{0} C_{2}+C_{0} r_{\mathrm{c}} H-(2.4 v+2.4) r_{\mathrm{c}}^{2}$,

$C_{6}=C_{0} C_{1}+C_{0} r_{\mathrm{c}} h, C_{7}=C_{0} h^{2}$,

$C_{8}=2 C_{0} H h-(2.4 v+1.4)\left(C_{1}+r_{\mathrm{c}} h\right)$,

$C_{9}=C_{0} H^{2}-(2.4 v+1.4)\left(C_{2}+r_{\mathrm{c}} H\right)$,

$C_{10}=(2.4 v+2.4) C_{1}^{2}+(4.8 v+4.8) r_{\mathrm{c}} C_{1} h$,

$C_{11}=(4.8 v+4.8)\left(C_{1} C_{2}+r_{\mathrm{c}} C_{1} H+r_{\mathrm{c}} C_{2} h\right)$,

$C_{12}=(2.4 v+2.4) C_{2}^{2}+(4.8 v+4.8) r_{\mathrm{c}} C_{2} H$,

$C_{13}=C_{4} C_{6}, C_{14}=C_{3} C_{6}+C_{4} C_{5}, C_{15}=C_{3} C_{5}$.

Thus, $\alpha$ can be obtained by solving Eq. (31) and the HT modulus of inner-side coating is determined by $E_{\mathrm{f}}=\alpha E_{\mathrm{sH}}$.

\subsubsection{Determining HT modulus of double-side coatings on ring samples}

For a split ring piece with double-side coating as shown in Fig. 7(c), assuming its cross-beam displacement is $\Delta \delta_{5}$ under the fixed load-increment $\Delta P$ at HT, the real HT deformation of the coated piece is $\Delta \delta=\Delta \delta_{5}-\Delta \delta_{2}$. Thus, Eq. (23) can be rewritten as

$$
\frac{2 E_{\mathrm{sH}}}{\pi} \frac{\Delta \delta_{5}-\Delta \delta_{2}}{\Delta P}=\frac{R_{0}^{\prime}}{A^{\prime}}\left(\frac{R_{0}^{\prime}}{e^{\prime}}+2.4 v+1.4\right)
$$

As shown in Fig. 7(c), $r_{\mathrm{c}}$ is the inner radius of the inner-side coating and $R_{\mathrm{c}}$ is the outer radii of the outer-side coating. $H$ is the thickness of the substrate and $H=R-r . h_{1}\left(h_{1}=R_{\mathrm{c}}-R\right)$ and $h_{2}\left(h_{2}=r-r_{\mathrm{c}}\right)$ are the thickness of the outer-side and inner-side coating, respectively. The geometrical analysis of the composite cross-section is conducted and, $A^{\prime}, R_{0}^{\prime}$, and $e^{\prime}$ have the forms:

$$
\begin{aligned}
A^{\prime}= & b H+\alpha b\left(h_{1}+h_{2}\right) \\
R_{0}^{\prime}= & \frac{\left[0.5 h_{2}^{2}+h_{1}\left(0.5 h_{1}+H+h_{2}\right)\right] \alpha+H\left(h_{2}+0.5 H\right)}{H+\alpha\left(h_{1}+h_{2}\right)}+r_{\mathrm{c}} \\
e^{\prime}= & \frac{\left[0.5 h_{2}^{2}+h_{1}\left(0.5 h_{1}+H+h_{2}\right)\right] \alpha+H\left(h_{2}+0.5 H\right)}{H+\alpha\left(h_{1}+h_{2}\right)} \\
& +r_{\mathrm{c}}-\frac{\alpha\left(h_{1}+h_{2}\right)+H}{\alpha\left[\ln \left(\frac{R_{\mathrm{c}}}{R}\right)+\ln \left(\frac{r}{r_{\mathrm{c}}}\right)\right]+\ln \left(\frac{R}{r}\right)}
\end{aligned}
$$

Combining Eqs. (33) and (34), a simplified relation among $E_{\mathrm{sH}}, \Delta P / \Delta \delta$, and $\alpha$ is derived by

$$
\phi_{1} \alpha^{4}+\phi_{2} \alpha^{3}+\phi_{3} \alpha^{2}+\phi_{4} \alpha+\phi_{5}=0
$$

where $\phi_{1}-\phi_{5}$ are the coefficients of the quartic equation and can be calculated by

$$
\begin{aligned}
& \phi_{1}=\left(D_{16}-D_{10}\right) D_{3}^{2} \\
& \phi_{2}=\left(D_{17}-D_{11}\right) D_{3}^{2}+2 D_{3} D_{4}\left(D_{16}-D_{10}\right)-D_{5} D_{13} \\
& \phi_{3}=\left(D_{18}-D_{12}\right) D_{3}^{2}+\left(D_{16}-D_{10}\right) D_{4}^{2}+2 D_{3} D_{4}\left(D_{17}-D_{11}\right) . \\
& \quad-D_{5} D_{14}-D_{6} D_{13} \\
& \phi_{4}=\left(D_{17}-D_{11}\right) D_{4}^{2}+2 D_{3} D_{4}\left(D_{18}-D_{12}\right)-D_{5} D_{15}-D_{6} D_{14} \\
& \phi_{5}=\left(D_{18}-D_{12}\right) D_{4}^{2}-D_{6} D_{15} \\
& \text { where } \quad D_{0}=\frac{2 E_{\mathrm{sH}} b}{\pi} \cdot \frac{\Delta \delta_{5}-\Delta \delta_{2}}{\Delta P}, \quad D_{1}=\frac{1}{2} h_{2}^{2} \\
&+h_{1}\left(\frac{h_{1}}{2}+H+h_{2}\right), \quad D_{2}=H\left(h_{2}+\frac{H}{2}\right), \quad D_{3}=h_{1}+h_{2},
\end{aligned}
$$


$D_{4}=H \quad, \quad D_{5}=\ln \left(\frac{R_{\mathrm{c}}}{R}\right)+\ln \left(\frac{r}{r_{\mathrm{c}}}\right), \quad D_{6}=\ln \left(\frac{R}{r}\right)$,

$D_{7}=D_{0} D_{1}+D_{0} D_{3} r_{\mathrm{c}}, \quad D_{8}=D_{0} D_{2}+D_{0} D_{4} r_{\mathrm{c}}, \quad D_{9}=D_{8}$

$-(2.4 v+2.4) r_{\mathrm{c}}^{2} \quad, \quad D_{10}=D_{0} D_{3}^{2} \quad, \quad D_{11}=2 D_{0} D_{3} D_{4}$

$-(2.4 v+1.4)\left(D_{1}+D_{3} r_{\mathrm{c}}\right), \quad D_{12}=D_{0} D_{4}^{2}-(2.4 v+1.4)$

$\cdot\left(D_{2}+D_{4} r_{\mathrm{c}}\right) \quad, \quad D_{13}=(2.4 v+2.4) D_{1}^{2}$

$+(4.8 v+4.8) D_{1} D_{3} r_{\mathrm{c}} \quad, \quad D_{14}=(4.8 v+4.8)$

$\cdot\left(D_{1} D_{2}+D_{2} D_{3} r_{\mathrm{c}}+D_{1} D_{4} r_{\mathrm{c}}\right) \quad, \quad D_{15}=(2.4 v+2.4) D_{2}^{2}+$

$(4.8 v+4.8) D_{2} D_{4} r_{\mathrm{c}} \quad, \quad D_{16}=D_{5} D_{7} \quad$,

$D_{17}=D_{5} D_{9}+D_{6} D_{7}, D_{18}=D_{6} D_{9}$.

Thus, $\alpha$ can be obtained by solving Eq. (35) and the HT modulus of inner-side coatings is determined by $E_{\mathrm{f}}=\alpha E_{\mathrm{sH}}$.

Obviously, the key for evaluating the HT modulus of the coatings on tubes is to obtain the accurate deformation of coated and uncoated samples, and the analytical relation among $E_{\mathrm{sH}}, \Delta P / \Delta \delta$, and $\alpha$. Relative method can be used to determine the HT modulus of the substrates via Eq. (22) for the first time, and then to measure the HT elastic modulus of coatings via Eqs. (26)-(28) for the outer coated piece, Eqs. (31) and (32) for the inner coated sample, and Eqs. (35) and (36) for the double coated specimen. The split ring compressing tests for determining the HT modulus of coatings by the relative method are performed in the following steps: 1) prepare the substrate, composite pieces, and rigid disks which have the same geometrical dimensions as the substrates and coated samples, 2) heat the substrate and rigid disk to the setting temperature and compress the samples in the elastic deformation range, 3) record the cross-beam displacement of the substrates and reference pieces and calculate the HT modulus of the substrate via Eq. (22), 4) compress the coated sample and rigid disk at HT and record each cross-displacement, 5) substitute the measured data and the geometrical dimensions of the coated piece into Eqs. (26)-(28), (31) and (32), and (35) and (36), 6) solve the Eqs. (26), (31), and (35). Thus, the HT moduli of coatings can be got by $E_{\mathrm{f}}=\alpha E_{\mathrm{sH}}$.

\section{Materials and experimental process}

To check the reliability of the relative method, silicon carbide $(\mathrm{SiC})$ coatings prepared by using chemical vapor deposition (CVD) method on graphite substrates were used as the testing samples. Graphite is an attractive material for HT application and has been widely used as structural material due to the excellent HT mechanical properties $[42,43]$. And $\mathrm{SiC}$ is being considered as a protective coating to protect the graphite from oxidation $[44,45]$ due to its excellent and superior properties of melting point, thermal shock resistance, and chemical inertness [46]. The mechanical properties of $\mathrm{SiC}$ coating are the essential prerequisites for achieving its functionality. Among them the HT elastic modulus of such coating material is of high importance, because it will determine the value of thermal residual stress which appears upon heating or cooling [47], define the lifetime of the materials, and play a major role in the reliability of the components as a whole. Whereas the in situ, accurate, and reliable elastic modulus of $\mathrm{SiC}$ coatings at high and ultrahigh temperature have not been discussed so far.

The homogeneous graphite was prepared by isostatic pressing method, while the CVD-SiC coatings were fabricated by pyrolysis of methyltrichlorosilane (MTS) in hydrogen $\left(\mathrm{H}_{2}\right)$ at $1300{ }^{\circ} \mathrm{C}$ and $5 \times 10^{3} \mathrm{~Pa}$ for $10 \mathrm{~h}$ with the coating thickness of about $60 \mu \mathrm{m}$ for the beam samples and $40 \mu \mathrm{m}$ for the ring pieces. During the preparation of $\mathrm{SiC}$ coating, the MTS flow rate was 0.75 $\mathrm{L} / \mathrm{min}$ and the volume ratio of $\mathrm{H}_{2}$ to MTS was controlled at 12:1 by a flowmeter. The prepared CVD-SiC coatings are polycrystalline structure as shown in Ref. [48], and the main phase is $\beta$-SiC. In order to obtain the reliable data, the ratio of the coating thickness to the substrate thickness should be larger than $1 / 100$, and the thickness of the coating shall be larger than $20 \mu \mathrm{m}$.

The sample dimensions were measured by a vernier caliper, and the average size of beam and ring samples is about $60 \mathrm{~mm}$ (length) $\times 10 \mathrm{~mm}$ (width) $\times 3 \mathrm{~mm}$ (thickness) and $12 \mathrm{~mm}$ (inner radius) $\times 15 \mathrm{~mm}$ (outer radius) $\times 7.2 \mathrm{~mm}$ (width), respectively. Furthermore, all the ring specimens were cut with the split of $6 \mathrm{~mm}$. At least three samples should be tested to obtain an average value. The rigid disk with the same outer radius and width as the split ring sample was made of graphite. The thickness of the $\mathrm{SiC}$ coatings was measured by the digital microscope (VHX-600, KEYENCE, Japan). Microstructures were examined using a scanning electron microscope (S-4800, Hitachi, Japan). The phase analysis and crystalline structures of the $\mathrm{SiC}$ coatings were investigated using an X-ray diffractometer (D8 ADVANCE, Brucker Corporation). 
The support span for the three-point bending tests was $50 \mathrm{~mm}$. The lower and upper limits of the load were 5-20 $\mathrm{N}$ and 4-10 $\mathrm{N}$ for the bending tests and split ring compressing experiments, respectively. The loading rate was controlled at $0.1 \mathrm{~mm} / \mathrm{min}$ by the cross-beam displacement for the both experiments. It is emphasized that, before the HT loading tests, the accuracy of cross-beam displacement should be calibrated by using an accurate inductance micrometer (MT 220, Qinghai Measuring \& Cutting Tools Group Company, China) in order to ensure the reliability of measured results. An empirical deviation within $0.5 \%$ would be acceptable in this work. The elevated temperature testing was performed in graphite heater furnace capable of reaching temperatures of $2300{ }^{\circ} \mathrm{C}$ under high vacuum (lower than $10^{-1} \mathrm{~Pa}$ ). The temperatures below $1200{ }^{\circ} \mathrm{C}$ were measured by thermocouple inserted from the side of the furnace and the temperatures exceeding $1200{ }^{\circ} \mathrm{C}$ were measured by an optical pyrometer. The furnace shall be capable of heating the test fixture, pushing rod and test piece as well as maintaining a uniform and constant temperature during the test. The heating rate for all elevated temperature tests was $10{ }^{\circ} \mathrm{C} / \mathrm{min}$ followed by a $20 \mathrm{~min}$ isothermal hold at the desired temperature. The HT loading experiments were performed by the mechanical testing instrument (DSZ-III, China Building Material Test \& Certification Center, China).

In order to verify the validity of the relative method, the tested results of the coating modulus measured by an inductance micrometer were compared with that evaluated by the difference of cross-beam displacement at room temperature. The room temperature loading tests were carried out by the universal mechanical testing machine (MTS Criterion C45, MTS Systems Corporation, America) with the cross-head speed of $0.1 \mathrm{~mm} / \mathrm{min}$. The mid-span deflection and the vertical displacement of the loading location were tested by an inductance micrometer at ambient temperature.

\section{Results and discussion}

\section{1 Validity of the relative method}

The graphite beam and ring samples coated with $\mathrm{SiC}$ coatings were used in this work. Figure 8 shows the cross-section micrograph of the coated piece. The boundary between the coating and substrate can be seen obviously and well connected with each other, with the dense $\mathrm{SiC}$ coating on the left side, which means that the coating is tightly integrated with the substrate and no slip occurred at the interface. Thus, the strain would

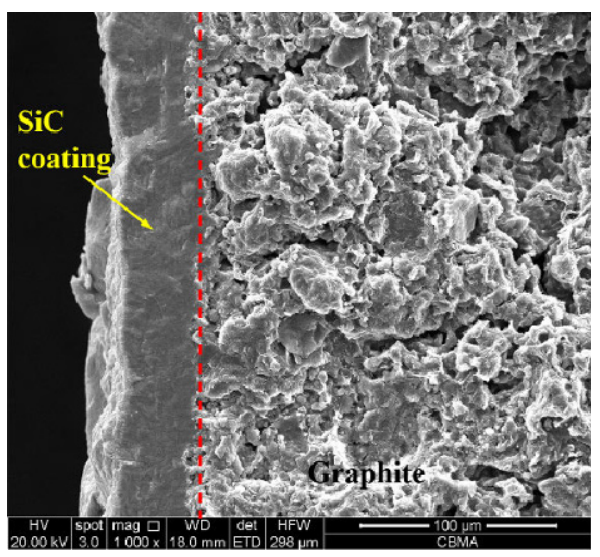

Fig. 8 Cross-section micrograph of the $\mathrm{SiC}$ coated graphite.

happen to change gently at the interface and the above mathematical derivations can be used effectively to evaluate the modulus of $\mathrm{SiC}$ coatings.

In order to verify the validity of the relative method combined with the three-point bending tests at room temperature, the mid-span deflections of the beam samples were determined directly by an inductance micrometer and tested indirectly via the difference of the cross-beam displacement between the bending sample and reference piece. Both the elastic modulus of graphite substrates and $\mathrm{SiC} /$ graphite composite systems were calculated by Eq. (1) via using the micrometer and Eq. (2) via the cross-beam displacement, with the tested results shown in Fig. 9. Both of the tested modulus of graphite substrates and $\mathrm{SiC} /$ graphite composites are basically the same. Plugging the tested data and the dimensions of composites into Eq. (9), the modulus of $\mathrm{SiC}$ coatings could be obtained. The mean value of

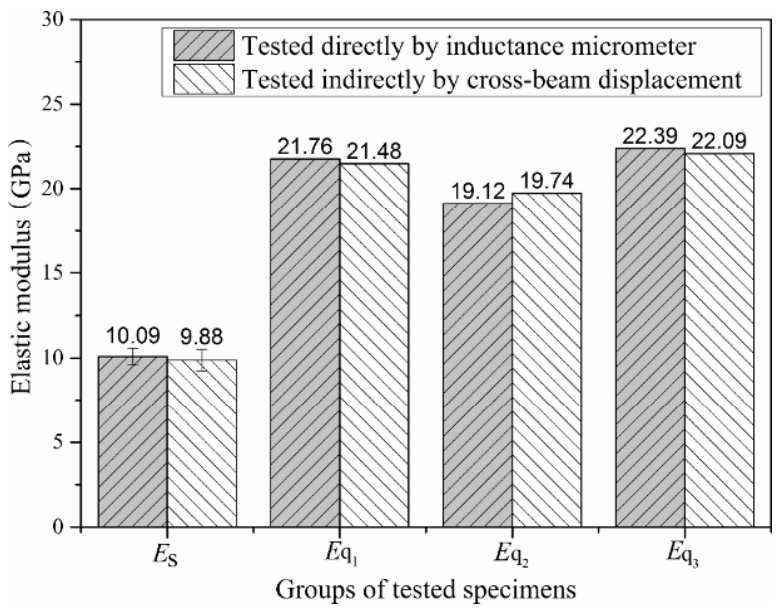

Fig. 9 Elastic modulus of graphite substrates and $\mathrm{SiC} /$ graphite composites at room temperature measured by three-point bending tests. 
elastic modulus of $\mathrm{SiC}$ coating was estimated as $373.27 \pm 18.33 \mathrm{GPa}$ via the micrometer (the relative method was used only once) and $391.23 \pm 10.76 \mathrm{GPa}$ via the cross-beam displacement (the relative method was used twice). The tested modulus of $\mathrm{SiC}$ coating shows a tiny deviation of $4.8 \%$ at room temperature. It has revealed that the approach which needs to use the relative method secondly is valid and reliable to determine the elastic modulus of coatings by the three-point bending test.

To verify the validity of the relative method combined with the split ring compressing tests at room temperature, the vertical displacement of the loading location was determined by the micrometer and the cross-beam displacement difference, respectively. The elastic modulus of the graphite substrates was obtained by Eq. (19) via using micrometer and Eq. (22) via the cross-beam displacement difference. The outer-side coating modulus was obtained by substituting the tested substrate modulus, vertical displacement, and geometrical dimensions of the $\mathrm{SiC} /$ graphite composite split ring piece into Eqs. (26)-(28). And the inner-side coating modulus was calculated by Eqs. (31) and (32). The tested and calculated data of the SiC/graphite composites are displayed in Table 1 . The mean values of the elastic modulus of the outer-side $\mathrm{SiC}$ coating were estimated as $383.69 \mathrm{GPa}$ tested and $387.00 \mathrm{GPa}$ by the micrometer and cross-beam displacement difference, respectively. Both of the two tested results are close and within the acceptable error range. The elastic modulus of the inner-side $\mathrm{SiC}$ coating measured by the micrometer was $378.76 \mathrm{GPa}$ which is very similar to that measured using the cross-beam displacement difference (383.78 GPa).

Table 1 Measure data of $\mathrm{SiC}$ coated on graphite substrate

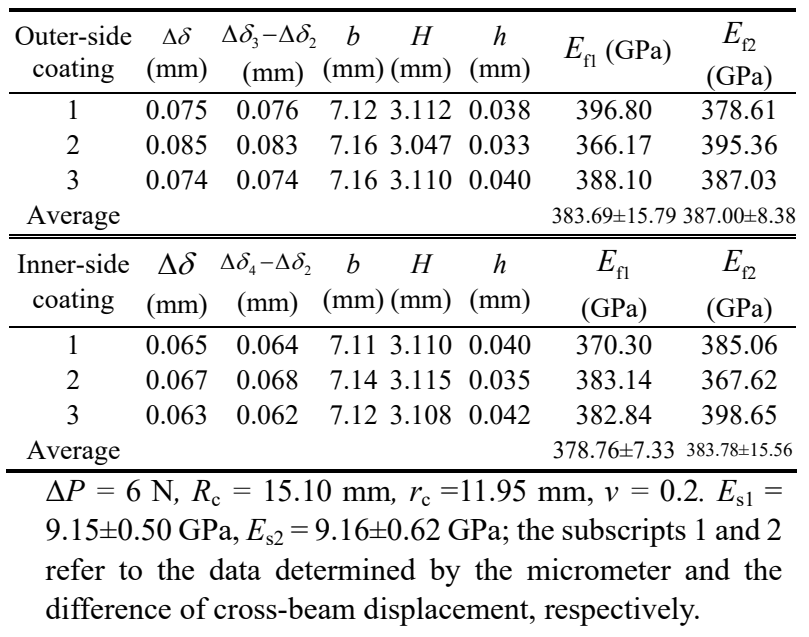

It can be seen that the systematic errors of loading system can be represented by the cross-beam displacement of the reference sample. The test results demonstrated that the relative method is valid and reliable to determine the elastic modulus of ceramic coatings by comparing to the tested results via micrometer, also it can be applied to evaluate the coating modulus at high and ultrahigh temperature.

\section{2 HT elastic modulus of SiC coatings evaluated by the relative method}

The single-face coated beam samples and split ring pieces with outer-side coatings were used to determine the elastic modulus of coatings at HT. The temperature dependence of elastic modulus of $\mathrm{SiC}$ coatings measured by the relative method is displayed in Fig. 10. The modulus of $\mathrm{SiC}$ coatings measured by relative three-point bending tests are accordant basically with that tested by relative split ring compressing experiments from ambient temperature to $2100{ }^{\circ} \mathrm{C}$. The measured modulus of $\mathrm{SiC}$ coating was $369.80 \pm 17.60 \mathrm{GPa}$ and $374.16 \pm 16.55 \mathrm{GPa}$, respectively, by relative three-point bending and split ring tests at room temperature. And the measured results are similar to the previous data reported by Bellan and Dhers (354 $\pm 30 \mathrm{GPa}$ ) [49], Liu and Xiang (320 GPa) [50], and Leisen et al. (347-366 GPa) [51] for CVD-SiC. For the relative three-point bending test results, the coating elastic modulus increased nearly linearly to $424.36 \mathrm{GPa}$ at $500{ }^{\circ} \mathrm{C}$, and steadily reduced to $381.05 \mathrm{GPa}$ at $1500{ }^{\circ} \mathrm{C}$. Above $1500{ }^{\circ} \mathrm{C}$, the coating modulus decreased quite rapidly to $194.78 \mathrm{GPa}$ at $2100{ }^{\circ} \mathrm{C}$ which declined nearly by $47.33 \%$ compared with the room temperature modulus. For the relative split ring compressing measurements, the similar temperature dependency of the $\mathrm{SiC}$ coating modulus was also discovered as shown in Fig. 10. The modulus of SiC coating increased to $438.04 \mathrm{GPa}$ at $500{ }^{\circ} \mathrm{C}$, and then decreased slightly to $381.88 \mathrm{GPa}$ at $1500{ }^{\circ} \mathrm{C}$. Above $1500{ }^{\circ} \mathrm{C}$, the coating modulus reduced dramatically to $204.99 \mathrm{GPa}$ at $2100{ }^{\circ} \mathrm{C}$.

Also the comparison among the measured temperature-modulus profile and the other measurements [51-54] is showed in Fig. 10. The several other tests have been performed between room temperature and $1500{ }^{\circ} \mathrm{C}$, and the used methods (micro-tensile test, 3-point/4-point bending test, and 


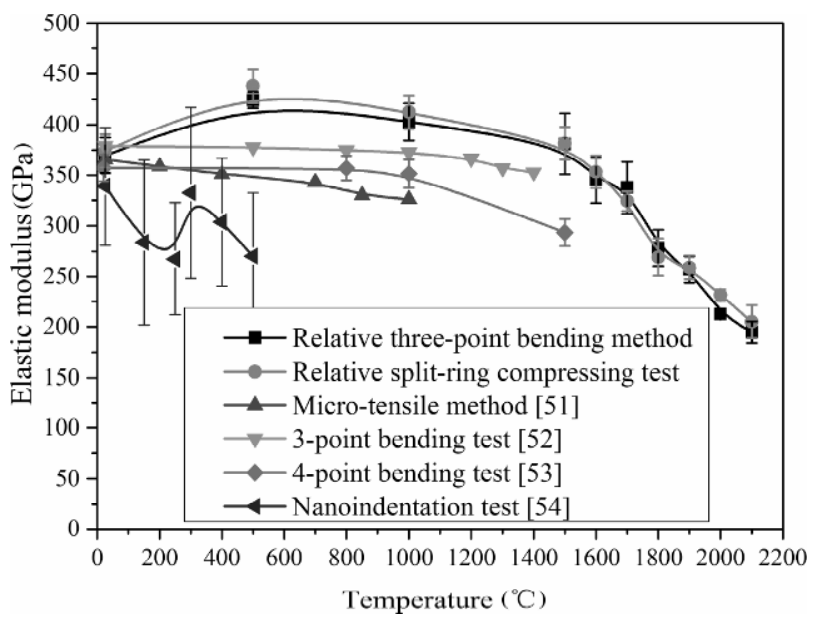

Fig. 10 Measured elastic modulus of $\mathrm{SiC}$ coatings from room temperature to HT from this work and other previous related measurements.

nanoindentation) can hardly be applied to determine the modulus at the ultrahigh temperature (over $1500{ }^{\circ} \mathrm{C}$ ) due to the invalidity of the previous methods. The elastic modulus-temperature profiles tested by this work and other previous researches are different as shown in Fig. 10, i.e., the elastic modulus measured by this work increased at first and then decreased, whereas the modulus tested by Refs. [51-53] just decreased with the rise of temperature. This difference is most probably caused by the different sample conditions, i.e., the HT modulus are measured in situ in this work, but the free-standing $\mathrm{SiC}$ samples were required to be used in Refs. [51-53]. The in situ measurements of the HT modulus of the $\mathrm{SiC}$ coatings are influenced by the thermal stress generated by the mismatch of the thermal expansion coefficients between the coating and substrate materials during the course of heating.

Although the in situ measurement of the coatings modulus can be realized by the nanoindentation, the measurement results of the nanoindentation [54] shows a large scatter because it allows only the investigation of the local modulus that are often different from the practical modulus. So the modulus measured by nanoindentation and relative method are not comparable. Also, the nanoindentation cannot work at higher temperature due to the oxidation and stiffness degradation of the indenter.

The observed increase and decrease in modulus must be a result of changes in the microstructure and the stress state of materials. The increase in modulus of $\mathrm{SiC}$ coatings from room temperature to $500{ }^{\circ} \mathrm{C}$ was correlated to the thermal compressive stress of the coating during the heating process. The microstructure and surface morphology of the $\mathrm{SiC}$ coating before and after the HT test was characterized using SEM. As shown in Fig. 11(a), the microcracks were observed on the coating surface. According to the research results of Wei et al. [34], the thermal expansion coefficient of SiC coating was greater than that of graphite substrate. So the coating was under compressive stress caused by the thermal mismatch during the heating process and the closure of microcracks may occur. The improvement in coating modulus was enabled by the reduction of the micro-defects. When the test temperature exceeding $500{ }^{\circ} \mathrm{C}$, the coating modulus decreased gradually due to the progressive weakening of the interatomic bonds with the rise of temperature. The strong modulus degradation occurred at temperatures higher than $1500{ }^{\circ} \mathrm{C}$, as shown in Fig. 10. This behavior was attributed primarily to grain-boundary sliding, thermal softening, and diffusional creep [55,56]. Simultaneously, the decrease in coating modulus is accelerated by the relaxation of residual compressive stress [57] in the SiC coating at HT.

From Fig. 11, a significant change in surface morphology before and after the HT test can be seen. The grain edges of the coatings can be detected clearly

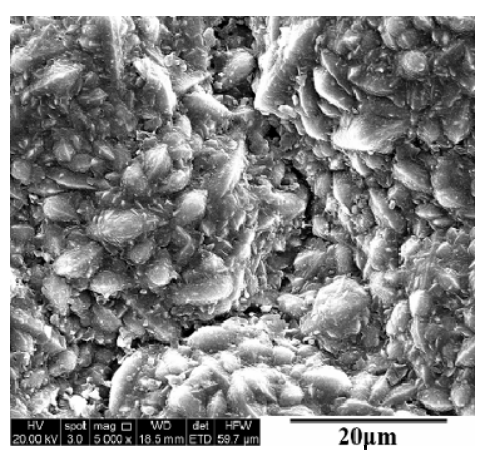

(a)

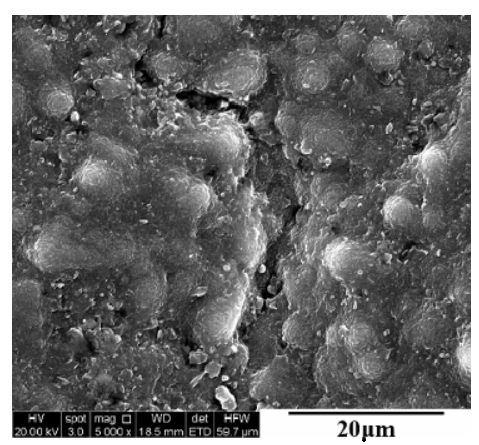

(b)

Fig. 11 SEM images of the SiC coating surface: (a) before the HT test, (b) after the HT test. 
before the HT test. However, the surface of the SiC coating is smooth after the HT test and the materials must generate softening under the HT environment. The decrease in modulus is enhanced by the softening of the materials.

The XRD measurements before and after the HT experiment are shown in Fig. 12. The $\beta$-SiC, stacking faults (SF), and graphite can be detected in the $\mathrm{SiC}$ coating before the HT test, and the $\alpha-\mathrm{SiC}$ is found in the $\mathrm{SiC}$ coating after $\mathrm{HT}$ test, i.e., $\beta$-SiC was transformed to $\alpha$-SiC at elevated temperature during the HT test. And the planar defects (stacking fault) concentration reduced after the HT test. The reduction in defects can improve the mechanical properties of materials. However, the progressive weakening of the interatomic bonds, thermal softening, and HT creep can decrease the elastic modulus, and the thermal degradation of the modulus is more obvious than the improvement of the modulus resulted by the defect reduction. Therefore, the HT elastic modulus decreased with the rise of temperature.

As shown in Fig. 10, the measured results of HT elastic modulus of $\mathrm{SiC}$ coatings by relative three-point bending tests were close to the tested results by relative split ring experiments. The both results could verify each other and showed the effectiveness and correctness of the relative method.

\section{Conclusions}

The HT elastic modulus of ceramic coatings was evaluated by using relative method via the three-point bending tests or split ring compressing experiments. The relative method was used twice: once to determine the real deformation of the test pieces at HT and again to derive the equations for calculating elastic modulus of the ceramic coatings via the properties of the substrate and composite. By this way, elastic modulus of ceramic coatings at high temperature shall be conveniently determined. Based on the mechanics of materials, the analytical equations were derived for two types of coated system: 1) single-face and double-face coatings on the beam substrates and 2) outer-side, inner-side, and double-side coatings on the ring substrates.

At ambient temperature, the deformations of the beam and ring samples, $\Delta f$ and $\Delta \delta$, were determined by an inductance micrometer and the cross-beam displacement difference between the test sample and rigid reference pieces, respectively. Then the modulus of $\mathrm{SiC}$ coatings on bulk graphite was calculated by substituting the measured $\Delta P$ and $\Delta f$ into Eqs. (1), (2), and (9). And the modulus of outer-side and inner-side $\mathrm{SiC}$ coatings on graphite tubes was calculated by substituting the tested $\Delta P$ and $\Delta \delta$ into Eqs. (26)-(28) and (31) and (32), respectively. Both the experimental results measured by the micrometer and relative method at room temperature were very close with slight relative deviations only, and show the validity of the relative method for evaluating the elastic modulus of ceramic coatings. It turns out that the systematic errors of the test machine can be represented

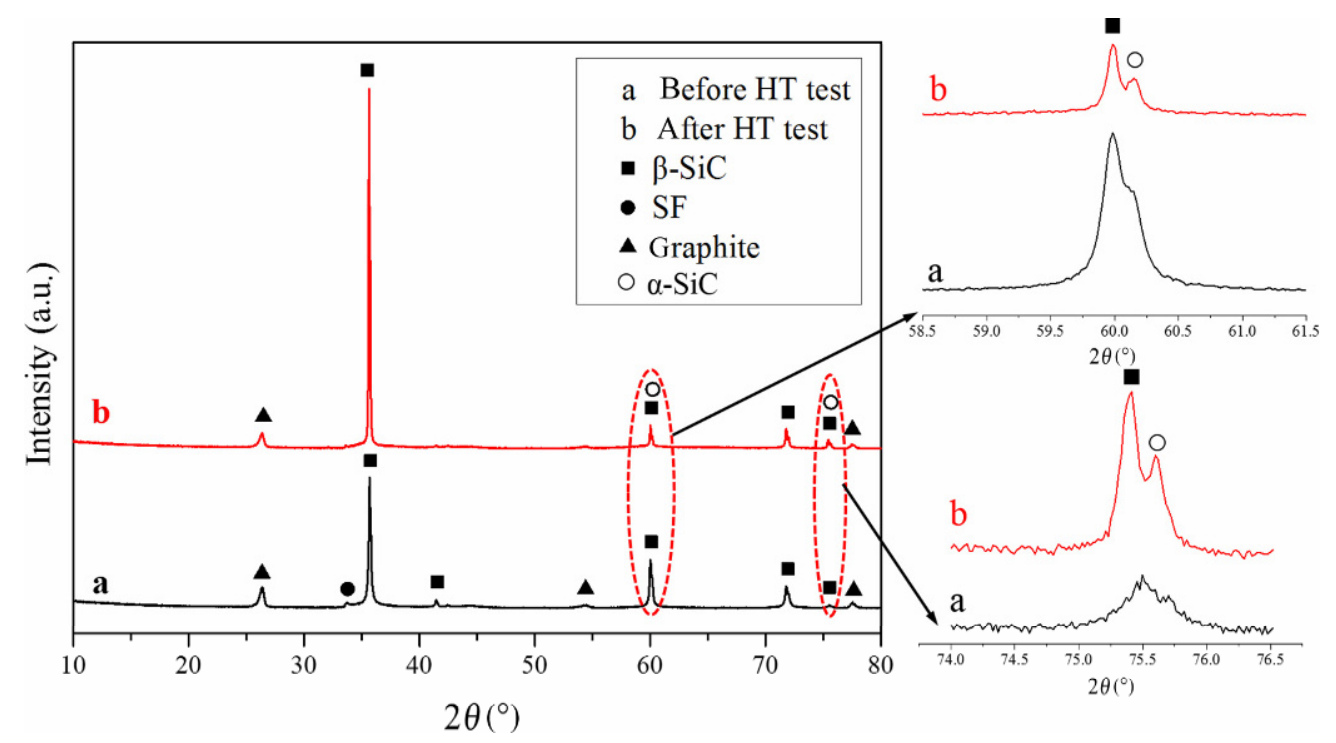

Fig. 12 XRD spectra of the SiC coating before and after HT experiment. 
by the rigid reference samples, thus the accurate deformation of the test specimens can be obtained by the cross-beam displacement difference. The simple method can also be applied to the evaluation of coating elastic modulus at high and ultrahigh temperature.

The deformations of the beam and ring samples at HT were determined by comparing the cross-beam displacements of the test machine between the test piece and rigid reference sample under identical load condition. The elastic modulus of $\mathrm{SiC}$ coatings on graphite beams and outside surface of graphite rings were evaluated by the relative method from room temperature to $2100{ }^{\circ} \mathrm{C}$. The temperature dependency of coating modulus measured by three-point bending tests accorded well with that tested by split ring compressing experiments. The results displayed that the coating modulus increased about $15.91 \%$ at $500{ }^{\circ} \mathrm{C}$ compared to the ambient temperature modulus, and then reduced with the increase of temperature. At temperatures over $1500{ }^{\circ} \mathrm{C}$, the coating's modulus decreased rapidly and reached only $53.73 \%$ of the room temperature modulus at $2100{ }^{\circ} \mathrm{C}$. It is demonstrated that the relative method is a convenient and accurate approach to evaluate the HT elastic modulus of ceramic coatings.

\section{Acknowledgements}

This work was supported by the National Natural Science Foundation of China (No. 51472227), and National High-tech R\&D Program of China (863 Program, No. 2015AA034204).

\section{References}

[1] Özel A, Ucar V, Mimaroglu A, et al. Comparison of the thermal stresses developed in diamond and advanced ceramic coating systems under thermal loading. Mater Design 2000, 21: 437-440.

[2] Lima CRC, Cinca N, Guilemany JM. Study of the high temperature oxidation performance of Thermal Barrier Coatings with HVOF sprayed bond coat and incorporating a PVD ceramic interlayer. Ceram Int 2012, 38: 6423-6429.

[3] Zhang Y-L, Li H-J, Yao X-Y, et al. Oxidation resistant $\mathrm{Si}-\mathrm{Mo}-\mathrm{Al}$ coating for $\mathrm{C} / \mathrm{SiC}$ coated carbon/carbon composites at high temperature. Surface Eng 2012, 28: 257-260.

[4] Yao D-J, Li H-J, Wu H, et al. Ablation resistance of $\mathrm{ZrC} / \mathrm{SiC}$ gradient coating for $\mathrm{SiC}$-coated carbon/carbon composites prepared by supersonic plasma spraying. $J$ Eur Ceram Soc 2016, 36: 3739-3746.

[5] Li H-J, Xue H, Wang Y-J, et al. $\mathrm{A} \mathrm{MoSi}_{2}-\mathrm{SiC}-\mathrm{Si}$ oxidation protective coating for carbon/carbon composites. Surf Coat Tech 2007, 201: 9444-9447.

[6] Yang Q, Senda T, Hirose A. Sliding wear behavior of WC-12\% Co coatings at elevated temperatures. Surf Coat Tech 2006, 200: 4208-4212.

[7] Scrivani A, Rizzi G, Bardi U, et al. Thermal fatigue behavior of thick and porous thermal barrier coatings systems. J Therm Spray Tech 2007, 16: 816-821.

[8] Keshavarz M, Idris MH, Ahmad N. Mechanical properties of stabilized zirconia nanocrystalline EB-PVD coating evaluated by micro and nano indentation. $J$ Adv Ceram 2013, 2: 333-340.

[9] Teixeira V. Numerical analysis of the influence of coating porosity and substrate elastic properties on the residual stresses in high temperature graded coatings. Surf Coat Tech 2001, 146-147: 79-84.

[10] Lee KS. Damage tolerance in hardly coated layer structure with modest elastic modulus mismatch. KSME Int $J$ 2003, 17: 1638-1649.

[11] Wei Q, Zhu J, Chen W. Anisotropic mechanical properties of plasma-sprayed thermal barrier coatings at high temperature determined by ultrasonic method. $J$ Therm Spray Tech 2016, 25: 605-612.

[12] Rajendran V, Karthik A, Srither SR, et al. Effect of high temperature on the surface morphology and mechanical properties of nanostructured $\mathrm{Al}_{2} \mathrm{O}_{3}-\mathrm{ZrO}_{2} / \mathrm{SiO}_{2}$ thermal barrier coatings. Surf Coat Tech 2015, 262: 154-165.

[13] Girolamo GD, Marra F, Schioppa M, et al. Evolution of microstructural and mechanical properties of lanthanum zirconate thermal barrier coatings at high temperature. Surf Coat Tech 2015, 268: 298-302.

[14] Girolamo GD, Marra F, Blasi C, et al. High-temperature mechanical behavior of plasma sprayed lanthanum zirconate coatings. Ceram Int 2014, 40: 11433-11436.

[15] Pulci G, Tului M, Tirillò J, et al. High temperature mechanical behavior of UHTC coatings for thermal protection of re-entry vehicles. $J$ Therm Spray Tech 2011, 20: $139-144$.

[16] Shang FL, Zhang X, Guo XC, et al. Determination of high temperature mechanical properties of thermal barrier coatings by nanoindentation. Surface Eng 2014, 30: 283-289.

[17] Eskner M, Sandström R. Mechanical properties and temperature dependence of an air plasma-sprayed NiCoCrAlY bondcoat. Surf Coat Tech 2006, 200: 2695-2703.

[18] Wheeler JM, Armstrong DEJ, Heinz W, et al. High temperature nanoindentation: The state of the art and future challenges. Curr Opin Solid St M 2015, 19: 354-366.

[19] Wheeler JM, Michler J. Invited article: Indenter materials for high temperature nanoindentation. Rev Sci Instrum 2013, 84: 101301.

[20] Wheeler JM, Oliver RA, Clyne TW. AFM observation of diamond indenters after oxidation at elevated temperatures. Diam Relat Mater 2010, 19: 1348-1353.

[21] Tillmann W, Selvadurai U, Luo W. Measurement of the Young's modulus of thermal spray coatings by means of several methods. J Therm Spray Tech 2013, 22: 290-298. 
[22] Liang L, Li X, Wei Y, et al. The mechanism of high thermal shock resistance of nanostructured ceramic coatings. Int $J$ Appl Ceram Technol 2015, 12: 1096-1102.

[23] Thornton J, Dale D, Ruff J, et al. Phase and strain mapping of a protective coating on carbon-carbon. Surf Coat Tech 2016, 287: 119-128.

[24] Yamada K, Tomono Y, Morimoto J, et al. Hot corrosion behavior of boiler tube materials in refuse incineration environment. Vacuum 2002, 65: 533-540.

[25] Liu J, Dyson D, Asselin E. Long-term hot corrosion behavior of boiler tube alloys in waste-to-energy plants. Oxid Met 2016, 86: 135-149.

[26] Zhang X. Coupled simulation of heat transfer and temperature of the composite rocket nozzle wall. Aerosp Sci Technol 2011, 15: 402-408.

[27] Barnett B, Trexler M, Champagne V. Cold sprayed refractory metals for chrome reduction in gun barrel liners. Int $J$ Refract Met H 2015, 53: 139-143.

[28] Li H, Chen G, Zhang K, et al. Degradation failure features of chromium-plated gun barrels with a laser-discrete-quenched substrate. Surf Coat Tech 2007, 201: 9558-9564.

[29] Zhong M, Liu W, Zhang H. Corrosion and wear resistance characteristics of $\mathrm{NiCr}$ coating by laser alloying with powder feeding on grey iron liner. Wear 2006, 260: 1349-1355.

[30] Uozato S, Nakata K, Ushio M. Evaluation of ferrous powder thermal spray coatings on diesel engine cylinder bores. Surf Coat Tech 2005, 200: 2580-2586.

[31] Chen YD, Feng Q, Zheng YR, et al. Formation of hole-edge cracks in a combustor liner of an aero engine. Eng Fail Anal 2015, 55: 148-156.

[32] Bao YW, Zhou YC, Bu XX, et al. Evaluating elastic modulus and strength of hard coatings by relative method. Mat Sci Eng A 2007, 458: 268-274.

[33] Wan D, Zhou Y, Bao Y. Evaluation of the elastic modulus and strength of unsymmetrical $\mathrm{Al}_{2} \mathrm{O}_{3}$ coating on $\mathrm{Ti}_{3} \mathrm{SiC}_{2}$ substrate by a modified relative methodology. Mat Sci Eng A 2008, 474: 64-70.

[34] Wei C, Liu Z, Bao Y, et al. Evaluating thermal expansion coefficient and density of ceramic coatings by relative method. Mater Lett 2015, 161: 542-544.

[35] Zhao Y, Bedekar V, Aning A, et al. Mechanical properties of high energy density piezoelectric ceramics. Mater Lett 2012, 74: 151-154.

[36] Malzbender J, Steinbrech RW. Substrate stiffness determination in curved layered composites using bending methods. Surf Coat Tech 2007, 202: 379-381.

[37] Wan D, Bao Y, Liu X, et al. Evaluation of elastic modulus and strength of glass and brittle ceramic materials by compressing a notched ring specimen. Adv Mater Res 2011, 177: $114-117$.

[38] ISO 18558:2015(E). Fine ceramics (advanced ceramics, advanced technical ceramics)-Test method for determining elastic modulus and bending strength of ceramic tube and rings. 2015.

[39] Liu Z, Bao YW, Wan DT, et al. A novel method to evaluate Young's modulus of ceramics at high temperature up to
$2100{ }^{\circ} \mathrm{C}$. Ceram Int 2015, 41: 12835-12840.

[40] Popov EP, Nagarajan S, Lu ZA. Mechanics of Materials, 2nd edn. Prentice-Hall International Inc., 1978.

[41] Beer FP, Johnston ER, Dewolf JT, et al. Mechanics of Materials, 6th edn. McGraw-Hill, 2012.

[42] Aliakbarpour S, Zakeri M, Rahimipour MR, et al. Effect of $\mathrm{SiC}$-mullite coatings on oxidation resistance of graphite. Adv Appl Ceram 2014, 113: 358-361.

[43] Peng W, Han W, Jin X, et al. Oxidation resistant zirconium diboride-silicon carbide coatings for silicon carbide coated graphite materials. $J$ Alloys Compd 2015, 629: 124-130.

[44] Agrawal AK, Sarkar PS, Singh B, et al. Application of $\mathrm{X}$-ray micro-CT for micro-structural characterization of APCVD deposited SiC coatings on graphite conduit. Appl Radiat Isotopes 2016, 108: 133-142.

[45] Rao PT, Jain U, Mollick PK, et al. Application of atmospheric CVD for internal surface coating of graphite conduit by silicon carbide. J Nucl Mater 2015, 456: 200-205.

[46] Varshney D, Shriya S, Jain S, et al. Mechanically induced stiffening, thermally driven softening, and brittle nature of SiC. J Adv Ceram 2016, 5: 13-34.

[47] Paul B, Prakash J, Sarkar PS. Formation and characterization of uniform $\mathrm{SiC}$ coating on 3-D graphite substrate using halide activated pack cementation method. Surf Coat Tech 2015, 282: 61-67.

[48] Huo Y, Chen Y. Effects of deposition temperature on the growth characteristics of CVD SiC coatings. Key Eng Mater 2008, 368-372: 846-848.

[49] Bellan C, Dhers J. Evaluation of Young modulus of CVD coatings by different techniques. Thin Solid Films 2004, 469-470: 214-220.

[50] Liu ZL, Xiang L. Effects of working pressure and substrate temperature on the structure and mechanical properties of nanocrystalline $\mathrm{SiC}$ thin films deposited by bias-enhanced hot filament chemical vapor deposition. Thin Solid Films 2014, 562: 24-31.

[51] Leisen D, Rusanov R, Rohlfing F, et al. Mechanical characterization between room temperature and $1000{ }^{\circ} \mathrm{C}$ of $\mathrm{SiC}$ free-standing thin films by a novel high-temperature micro-tensile setup. Rev Sci Instrum 2015, 86: 055104.

[52] Chollon G, Naslain R, Prentice C, et al. High temperature properties of $\mathrm{SiC}$ and diamond CVD-monofilaments. J Eur Ceram Soc 2005, 25: 1929-1942.

[53] Cockeram BV. Fracture strength of plate and tubular forms of monolithic silicon carbide produced by chemical vapor deposition. J Am Ceram Soc 2002, 85: 603-610.

[54] Park K-I, Kim J-H, Lee H-K, et al. High temperature mechanical properties of CVD-SiC thin films. Mod Phys Lett B 2009, 23: 3877-3886.

[55] Neuman EW, Hilmas GE, Fahrenholtz WG. Mechanical behavior of zirconium diboride-silicon carbide-boron carbide ceramics up to $2200^{\circ} \mathrm{C}$. J Eur Ceram Soc 2015, 35: 463-476.

[56] Zhao G, Huang C, Liu H, et al. Microstructure and mechanical properties of hot pressed $\mathrm{TiB}_{2}-\mathrm{SiC}$ composite ceramic tool materials at room and elevated temperatures. Mat Sci Eng A 2014, 606: 108-116. 
[57] Beake BD, Fox-Rabinovich GS. Progress in high temperature nanomechanical testing of coatings for optimising their performance in high speed machining. Surf Coat Tech 2014, 255: 102-111.

Open Access The articles published in this journal are distributed under the terms of the Creative Commons Attribution
4.0 International License (http://creativecommons. org/licenses/by/4.0/), which permits unrestricted use, distribution, and reproduction in any medium, provided you give appropriate credit to the original author(s) and the source, provide a link to the Creative Commons license, and indicate if changes were made. 